\title{
Parental characteristics and perspectives pertaining to neonatal visits to the emergency department: a multicentre survey
}

\author{
JoAnn Harrold MD, Mélissa Langevin MD, Nick Barrowman PhD, Ann E. Sprague RN PhD, \\ Deshayne B. Fell PhD, Katherine A. Moreau PhD, Thierry Lacaze-Masmonteil MD, Suzanne Schuh MD, \\ Gary Joubert MD, Andrea Moore MD, Tanya Solano MD, Roger L. Zemek MD; for the Pediatric \\ Emergency Research Canada Network
}

Abstract

Background: Parents take neonates to the emergency department for many reasons, often nonurgent, pressuring an already burdened system. We aimed to characterize these visits and families to identify potential strategies to decrease neonatal emergency department visits.

Methods: We developed and implemented a survey that explored characteristics of neonates and parents/guardians evaluated in the emergency department, perspectives of parents and use of health care services. Parents presenting with a neonate to the emergency department in 5 large academic hospitals in Ontario were surveyed between December 2013 and June 2015 . We used descriptive statistics to report survey data and explored correlations between factors.

Results: A total of 1533 surveys were completed. The most common reasons for presenting were jaundice (441 [28.8\%]) and feeding issues (251 [16.4\%]). The majority of respondents (73.9\% [1104/1494]) had received advice before going to the emergency department. In most cases (86.4\% [954/1104]), this was from a health care provider, who frequently advised going to the emergency department. Although most parents (86.8\% [1280/1475]) reported high confidence in caring for a sick or injured child, $42.3 \%$ $(643 / 1519)$ were unsure of the severity, and most (90.4\% [578/639]) of these parents felt that the infant required assessment immediately or the same day. Of parents who felt the condition was not serious, $83.2 \%(198 / 238)$ thought that same-day evaluation was required. Nearly half of respondents $(44.4 \%$ [621/1400]) said they would have gone to their health care provider with a same-day appointment, and $28.1 \%$ (344/1225) would have gone to their care provider with a next-day appointment.

Interpretation: Parents' reported confidence in caring for sick or injured infants does not match the perceived urgency of neonatal conditions, which likely contributes to emergency department overuse. Any system to decrease nonurgent emergency department use by neonates would need to be immediately responsive, providing same-day help.

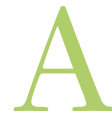

s emergency department visits increase, health care systems require strategies to deal with nonurgent emergency department use in more effective ways while refocusing limited resources on higher-acuity cases. This becomes particularly complicated in the case of infants and young children, who depend on parents to determine whether urgent medical attention is required. Indeed, up to $41 \%$ of children are brought to emergency departments in their first year, ${ }^{1-7}$ with $25 \%-50 \%$ visiting more than once $e^{2,3,5}$ and $49 \%-70 \%$ presenting with nonurgent concerns. ${ }^{5,8,9}$ Much less is known about neonatal visits (within $28 \mathrm{~d}$ of birth), although Lee and colleagues, ${ }^{10}$ in a nationally representative study in the United States, estimated that $7.6 \%$ of newborns had an emergency department visit within this period. In Ontario, that could mean that, of the roughly
140000 annual births, ${ }^{11}$ about 10640 neonates may visit an emergency department each year, with up to 7448 visits $(70.0 \%)$ being nonurgent.

In Ontario, most babies are born in hospital and are subsequently followed in the community by a family physician, pediatrician or midwife within a few days. Ante-/postnatal education is not standardized across institutions or practitioners.

Competing interests: None declared.

This article has been peer reviewed.

Correspondence to: JoAnn Harrold, jharrold@cheo.on.ca

CMAJ Open 2018. DOI:10.9778/cmajo.20180015 
Neonatal emergency department visits are often related to parental concerns inadequately addressed in the transition from hospital to home and may occur before the first scheduled appointment with the primary care provider. We wanted to learn what drives these visits and whether there are better alternatives to an emergency department visit. We conducted a quantitative survey to explore the characteristics of newborns and their parents who attend the emergency department within 28 days of birth. The survey was also designed to explore parents' perspectives on their experiences with the health care system before the emergency department visit.

\section{Methods}

\section{Setting and participants}

Parents or guardians presenting with a neonate to the emergency department at 1 of 5 Ontario academic health science centres (Children's Hospital of Eastern Ontario, Ottawa, Hotel Dieu Hospital, Kingston, London Health Sciences Centre, McMaster Health Sciences Centre, Hamilton, or The Hospital for Sick Children, Toronto) were eligible for the survey. Parents of neonates requiring resuscitation were excluded as it was not thought to be appropriate to approach them while their baby was unstable. Also excluded were parents who were unable to read English or French sufficiently to complete the survey. Surveys were distributed between December 2013 and June 2015, with all sites participating for a minimum of 6 months.

We used a convenience sampling approach, with survey distribution strategies varying by site based on local emergency department work flow. We expected about 5000 emergency department visits to the 5 hospitals in a 1 -year period and targeted a sample size of 1500 completed surveys. In all centres, hospital staff or research volunteers gave eligible parents a survey along with a cover letter explaining that participation in the study was voluntary and that returning the completed survey implied consent to participate. Surveys were completed anonymously in the hospital at the time of the emergency department visit, collected locally and returned in batches to the coordinating site. No incentives were provided for survey completion.

\section{Survey tool development}

Since no validated survey instrument exists for this patient population and setting, a survey was developed by researchers at the coordinating site (J.H., M.L., K.A.M., R.L.Z.). We employed a widely used framework for analyzing factors associated with use of health care services, ${ }^{12}$ existing literature on reasons for and predictors of emergency department use in pediatrics, and the expertise of the research team to develop the survey. We mapped each survey item to 1 of the following domains: environment (health care system and external environment), population (predisposing, enabling and need) and health behaviour (personal health choices and use of health care services). We then assessed for duplication among items and reduced their number to balance the domains, decrease redundancy and ensure a manageable final number of items.
Face validity of the survey was established by expert reviewers in pediatric emergency medicine, including K.A.M. and R.L.Z. The survey was piloted for usability, acceptability and user input with 60 families at the coordinating site. It was adjusted according to the pilot results, and the final version was translated into French. The survey can be found in Appendix 1 (available at www.cmajopen.ca/content/6/3/E423/ suppl/DC1).

\section{Statistical analysis}

The data were entered centrally into a secure research database $\left(\right.$ REDCap $\left.^{13}\right)$ by a research assistant. Partially completed surveys were included, and proportions were calculated relative to the number of respondents who answered each question. The primary analysis entailed a descriptive summary of characteristics of neonates and parents visiting the emergency department, with the use of frequencies and percentages. We assessed and compared demographic characteristics of eligible and surveyed emergency department visits using the Pearson $\chi^{2}$ test or the Fisher exact test, as appropriate. Two-sided $p$ values $<0.05$ were considered statistically significant. We performed exploratory secondary data analysis to examine potential correlations of variables after reviewing the results of the primary analysis. We conducted all data analyses using the $\mathrm{R}$ language version 3.3.1 (R Foundation for Statistical Computing, https://www.R-project.org/).

\section{Ethics approval}

Each participating site obtained research ethics board approval for the study. All participant responses remained confidential, and only aggregate data are reported.

\section{Results}

A total of 1533 surveys were received from 8610 potentially eligible emergency department visits. Rates were calculated based on the number of respondents to each question, and therefore the denominator changes frequently and is shown for transparency.

A comparison of the surveyed population and the eligible population is presented in Table 1 . The surveyed population was slightly underrepresented for weekend visits and visits between 0000 and 0800 but did not differ from the eligible population for age at presentation or infant sex.

Most babies were born at term, were never separated from their mother and were discharged within 48 hours of birth. Table 2 summarizes the characteristics of the birth and the hospital stay. In describing their infant, $88.8 \%$ of parents/ guardians $(1295 / 1459)$ agreed that their infant was as healthy as other babies, $15.8 \%(226 / 1426)$ agreed that their infant was more fragile than other babies, 8.5\% (119/1393) agreed that their infant got sick more easily than other babies, and $6.3 \%$ $(87 / 1386)$ agreed that their infant had a long-term health condition. The majority of participants were married, had college or university education, and had a family annual income of $\$ 50000$ or more (Appendix 2, available at www.cmajopen.ca/ content/6/3/E423/suppl/DC1). 


\begin{tabular}{|c|c|c|c|}
\hline \multirow[b]{2}{*}{ Characteristic } & \multicolumn{2}{|c|}{ No. (\%) of patients } & \multirow[b]{2}{*}{$p$ value } \\
\hline & $\begin{array}{c}\text { Eligible } \\
n=8610\end{array}$ & $\begin{array}{l}\text { Surveyed } \\
n=1533\end{array}$ & \\
\hline Sex & & & 0.5 \\
\hline Male & $4801(55.8)$ & $836(54.8)$ & \\
\hline Female & 3809 (44.2) & $688(45.1)$ & \\
\hline Missing & 0 & 9 & \\
\hline Age group, d & & & 0.4 \\
\hline$\leq 3$ & 1089 (12.6) & $202(13.2)$ & \\
\hline $4-7$ & 1958 (22.8) & $371(24.2)$ & \\
\hline $8-14$ & $1996(23.2)$ & 367 (23.9) & \\
\hline $15-21$ & 1786 (20.8) & 305 (19.9) & \\
\hline $22-28$ & 1774 (20.6) & $288(18.8)$ & \\
\hline Missing & 7 & 0 & \\
\hline Day of week & & & 0.01 \\
\hline Sunday & 1210 (14.0) & $163(10.8)$ & \\
\hline Monday & 1264 (14.7) & $245(16.2)$ & \\
\hline Tuesday & 1160 (13.5) & $230(15.2)$ & \\
\hline Wednesday & 1199 (13.9) & $218(14.4)$ & \\
\hline Thursday & 1135 (13.2) & $216(14.3)$ & \\
\hline Friday & 1346 (15.6) & $229(15.1)$ & \\
\hline Saturday & 1296 (15.0) & $211(14.0)$ & \\
\hline Missing & 0 & 21 & \\
\hline Visit time & & & $<0.001$ \\
\hline 0800-1659 & 3965 (46.0) & 767 (50.9) & \\
\hline 1700-2359 & 3387 (39.3) & $653(43.3)$ & \\
\hline 0000-0759 & $1258(14.6)$ & $87(5.8)$ & \\
\hline Missing & 0 & 26 & \\
\hline Site & & & $<0.001$ \\
\hline A & 2303 (26.7) & $947(61.8)$ & \\
\hline B & $1428(16.6)$ & $185(12.1)$ & \\
\hline C & 309 (3.6) & $32(2.1)$ & \\
\hline D & $178(2.1)$ & $33(2.2)$ & \\
\hline$E$ & 4392 (51.0) & $336(21.9)$ & \\
\hline
\end{tabular}

\section{Contact with health care system}

Of the $87.8 \%$ of parents $(1276 / 1454)$ who reported being asked in the birth hospital whether they had a health care provider (e.g., family doctor, pediatrician, midwife, nurse practitioner) for their baby, $80.2 \%(1005 / 1253)$ said they were also asked whether they had an appointment scheduled after discharge. On the survey, most parents (90.6\% [1356/1496]) indicated having a health care provider. The majority $(76.7 \%$ [1029/1342]) had had an appointment with their health care provider between discharge from the birth hospital and the emergency department visit. Finally, 35.9\% of parents

\begin{tabular}{|lc|}
\hline \multicolumn{2}{|l|}{ Table 2: Characteristics of delivery/infant/hospital stay } \\
\hline Characteristic & No. $(\%)$ \\
\hline Type of delivery $(n=1459)$ & $335(23.0)$ \\
\hline Cesarean & $1124(77.0)$ \\
\hline Vaginal & $19(1.3)$ \\
\hline Gestational age $(n=1467)$ & $227(15.5)$ \\
\hline$<35$ wk & $1202(81.9)$ \\
\hline 35 wk to 37 wk and 6 d & $19(1.3)$ \\
\hline 38 wk to 41 wk and 6 d \\
\hline$\geq 42$ wk \\
\hline $\begin{array}{l}\text { Separation of mother and baby } \\
(n=1447)\end{array}$ \\
\hline No, always with mother & $1270(87.8)$ \\
\hline Yes, baby was sick/small & $157(10.8)$ \\
\hline Yes, mother was sick & $20(1.4)$ \\
\hline Length of stay, h $(n=1453)$ & $145(10.0)$ \\
\hline$<24$ & $510(35.1)$ \\
\hline $24-36$ & $347(23.9)$ \\
\hline $37-48$ & $333(22.9)$ \\
\hline $49-96$ & $72.0)$ \\
\hline$>96$ & \\
\hline Not applicable/born at home & \\
\hline & \\
\hline & \\
\hline & \\
\hline & \\
\hline
\end{tabular}

(470/1309) with a health care provider reported that they could contact the office outside of regular hours.

In $8.8 \%$ of cases (133/1513), parents reported having taken the baby to the emergency department previously, and $61.2 \%$ (79/129) of these repeat visits occurred for the same concern. The majority of repeat visits $(74.1 \%$ [86/116]) were within 7 days of the index emergency department visit; $40.5 \%$ (47/116) were within 2 days. Recurrent visits due to the same problem occurred sooner than those due to a different prob$\operatorname{lem}(p=0.01)$.

\section{Clinical issues}

Just over half of parents (54.5\% [792/1453]) identified a single presenting problem, $23.8 \%$ (346/1453) identified 2 problems, and $21.7 \%(315 / 1453)$ reported more than 2 problems. Table 3 outlines the reasons for the visit. Jaundice, feeding issues, elimination problems, respiratory issues, fever and crying were the most commonly reported concerns.

\section{Advice and family management before emergency department visit}

The majority of parents (73.9\% [1104/1494]) had received advice from someone before going to the emergency department. In most cases (86.4\% [954/1104]), this advice came from a health care provider. Almost half of parents (46.7\% [622/1332]) with a usual health care provider contacted their care provider before going to the emergency department, and $67.5 \%$ of these parents $(420 / 622)$ were advised to take the baby to the emergency department. 


\begin{tabular}{|c|c|}
\hline Issue & $\begin{array}{l}\text { No. }(\%) \text { of } \\
\text { respondents* }\end{array}$ \\
\hline Gastrointestinal & $926(60.4)$ \\
\hline Jaundice/yellow colour of skin or eyes & $441(47.6)$ \\
\hline Feeding problem & $251(27.1)$ \\
\hline Vomiting & $201(21.7)$ \\
\hline Problem with stool & 179 (19.3) \\
\hline Diarrhea & $109(11.8)$ \\
\hline Ate something she/he should not have & $1(0.1)$ \\
\hline Respiratory & $403(26.3)$ \\
\hline Congestion & $249(61.8)$ \\
\hline Trouble breathing & $222(55.1)$ \\
\hline Cough & $190(47.1)$ \\
\hline Choked & $31(7.7)$ \\
\hline Apnea/apparent life-threatening event & $6(1.5)$ \\
\hline Neurological: shaking/tremor/seizure & $16(1.0)$ \\
\hline Trauma & $70(4.6)$ \\
\hline Lump/bump/swelling/abscess & $38(54.3)$ \\
\hline Fall & $14(20.0)$ \\
\hline Possible broken bone & $12(17.1)$ \\
\hline Motor vehicle crash/other accident & $5(7.1)$ \\
\hline Cut/scrape/bruise & $2(2.8)$ \\
\hline Cardiac: murmur/other & $14(0.9)$ \\
\hline Behavioural & $206(13.4)$ \\
\hline Crying & $135(65.5)$ \\
\hline Sleep problem & $99(48.0)$ \\
\hline $\begin{array}{l}\text { Lethargy/difficult to waken/acting } \\
\text { "different" }\end{array}$ & $19(9.2)$ \\
\hline Skin/dermatologic & $194(12.6)$ \\
\hline Rash & $82(42.3)$ \\
\hline Problem with eyes/eye discharge & $80(41.2)$ \\
\hline Redness/discharge near cord stump & $36(18.6)$ \\
\hline Allergic reaction & $7(3.6)$ \\
\hline Skin or nail colour & $4(2.1)$ \\
\hline Infectious & $150(9.8)$ \\
\hline Fever & $138(92.0)$ \\
\hline Thrush & $8(5.3)$ \\
\hline Infection & $4(2.7)$ \\
\hline Urinary & $106(6.9)$ \\
\hline Problem with urine & $85(80.2)$ \\
\hline Circumcision & $24(22.6)$ \\
\hline Other & $16(1.0)$ \\
\hline Examination & $4(25.0)$ \\
\hline Vaginal secretion/bleeding & $4(25.0)$ \\
\hline Syndrome/anomaly & $4(25.0)$ \\
\hline Problem with ear & $3(18.8)$ \\
\hline Doctor referral & $1(6.2)$ \\
\hline Do not know & $39(2.5)$ \\
\hline
\end{tabular}

The most commonly reported reasons for not contacting the usual health care provider included being unable to reach the care provider, receiving advice to go to the emergency department, believing the problem was more appropriate for or might require tests in the emergency department, or feeling that the care provider would refer the baby to emergency department anyway. Some parents (18.1\% [268/1477]) attempted treatment (e.g., feeding, comfort measures, acetaminophen administration) at home before presenting to the emergency department.

\section{Perceptions of severity and urgency}

Most parents (86.8\% [1280/1475]) reported being quite or very confident to take care of a sick or injured child. This rate was higher among respondents with another child in the home than among those without $(93.5 \%$ v. $79.1 \%)(p<0.001)$.

A total of $42.3 \%$ of parents [643/1519]) were not certain of the severity of their infant's condition, and most (90.4\% [578/639]) of these parents felt that the infant required assessment immediately or the same day; $18.1 \%$ (114/629) believed that something bad might happen if the baby was not seen within 24 hours. Of the $16.0 \%$ of parents $(243 / 1519)$ who described their infant's condition as not very serious, $83.2 \%(198 / 238)$ felt that same-day assessment was required, and $14.9 \%(36 / 242)$ believed that something bad might happen if the baby was not seen within 24 hours (Table 4).

About half of parents (50.8\% [764/1504]) expected that their infant would be seen in the emergency department within 1 hour.

\section{Exposure to information about babies}

Most parents reported having received information on common infant health topics, often from multiple sources (Table 5); 22.1\% (315/1424) said they had received conflicting or confusing advice. Parents who took their child to the emergency department with jaundice were more likely to report having received advice about jaundice than those who took their child to the emergency department for other reasons $(96.4 \%$ v. $91.3 \%)(p<0.001)$.

\section{Redirection to other health care resources}

Parents rated the following resources somewhat or very helpful in deciding whether to take their baby to the emergency department: walk-in clinic with pediatric specialist $(74.2 \%$ [973/1311]), 24-hour telephone advice from pediatric nurse or doctor $(73.5 \%$ [984/1338]), easier access to baby's doctor (72.5\% [948/1307]), postnatal home visit by nurse or doctor (70.6\% [918/1301]), reading material provided during the birth hospital stay (64.7\% [861/1330]), information on the Internet (58.8\% [777/1322]), and information in newspapers/ magazines or on television/radio (34.8\% [458/1316]). When asked whether an appointment with a health care provider would have prevented the emergency department visit, $44.4 \%$ of parents (621/1400) said yes for a same-day appointment, and $28.1 \%(344 / 1225)$ said yes if the appointment was within 24 hours. 


\begin{tabular}{|lcccc|}
\hline $\begin{array}{l}\text { Table 4: Parent/guardian perception of illness severity in terms of urgency and } \\
\text { expected outcome }\end{array}$ & \multicolumn{3}{l|}{ Perceived illness severity; no. (\%) of respondents } \\
\hline & $\begin{array}{c}\text { Not very } \\
\text { serious }\end{array}$ & Serious & serious & Not sure \\
\cline { 2 - 5 } Urgency/outcome & $n=238$ & $n=478$ & $n=149$ & $n=639$ \\
\hline Urgency to be seen & $73(30.7)$ & $219(45.8)$ & $117(78.5)$ & $241(37.7)$ \\
\hline Immediately & $125(52.5)$ & $227(47.5)$ & $28(18.8)$ & $337(52.7)$ \\
\hline Today & $40(16.8)$ & $32(6.7)$ & $4(2.7)$ & $61(9.5)$ \\
\hline Within a few days & & & & \\
\hline $\begin{array}{l}\text { Will something bad } \\
\text { happen if not seen } \\
\text { within 24 h? }\end{array}$ & $n=242$ & $n=475$ & $n=147$ & $n=629$ \\
\hline Definitely not & $33(13.6)$ & $9(1.9)$ & $1(0.7)$ & $17(2.7)$ \\
\hline Probably not & $110(45.4)$ & $100(21.0)$ & $13(8.8)$ & $125(19.9)$ \\
\hline Probably & $29(12.0)$ & $155(32.6)$ & $43(29.2)$ & $96(15.3)$ \\
\hline Definitely & $7(2.9)$ & $59(12.4)$ & $41(27.9)$ & $18(2.9)$ \\
\hline Do not know & $63(26.0)$ & $152(32.0)$ & $49(33.3)$ & $373(59.3)$ \\
\hline
\end{tabular}

\section{Interpretation}

Our results provide a perspective on why parents take their infant to the emergency department, highlighting that both parents and health care providers see neonates as in need of expedient, often same-day, care and that unilateral interventions are unlikely to be successful. The finding that a majority of parents reached out to health care providers before making a decision to go to the emergency department suggests an opportunity to direct parents to other available resources. Our results also show that, although parents have an opinion as to the severity of their infant's condition, they are uncertain. This is likely a major contributor to the decision to seek care in the emergency department rather than in another health care setting. This is reinforced by our finding that nearly half of respondents said they would have gone to their health care provider if they could have been seen the same day, whereas if the appointment were the next day, just over a quarter of respondents would have gone to their health care provider.

Previous studies showed that a high proportion of children have an identified primary care provider, ${ }^{14,15}$ and our findings confirm this for the neonatal population. In the current study, failure to ask whether the family had an appointment with their health care provider before discharge from the birth hospital was a missed opportunity to reinforce the importance of early postdischarge follow-up in nearly $20 \%$ of cases. Like other investigators, ${ }^{10,16-18}$ we found that low-acuity presentations of gastrointestinal issues, including jaundice and problems with feeding or stooling, were the most frequent causes for emergency department visits, along with respiratory concerns, crying and rash. Also consistent with the pediatric literature, ${ }^{14,15,19,20}$ repeated visits to the emergency department, often for the same issue, were frequent, even though most respondents reported having a health care provider for their baby. This suggests that the emergency department consultation may not always provide complete reassurance or support for parental concerns. The fact that most parents had seen their health care provider between discharge from the birth hospital and the emergency department visit indicates that an early appointment did not prevent presentation to the emergency department. This may be in part due to the fact that, although most parents reported a high level of confidence for taking care of a sick or injured child, a large proportion were unsure of the severity of their infant's condition and believed that it was sufficiently urgent to warrant being seen the same day. Even in cases in which parents thought that their infant's condition was not serious, many thought that being seen the same day was important. This is consistent with previous studies indicating that parents, including those of children whose condition is triaged as nonurgent, have difficulty discerning the urgency of the situation and frequently report it as very/extremely urgent. ${ }^{20,21}$ Furthermore, even though the majority of parents sought advice before going to the emergency department, health care providers generally advised that the baby be seen in the emergency department, a trend that is well documented in older pediatric patients. ${ }^{14,15,19,20,22}$

Education is often used to modify health behaviours, and there is evidence that education can affect rates of presentation to the emergency department in the infant population. For example, a provincial public health prevention program focused on crying led to a decreased rate of emergency department presentation among infants less than 5 months of age. ${ }^{23}$ However, education alone may not be sufficient. Our finding that parents of babies presenting with jaundice were more likely than other parents to have received information on hyperbilirubinemia may indicate that families were sensitized to the issue but were not well informed as to where to seek care. Parents in our study had generally received 
Table 5: Advice/information received by parent/guardian and timing/source of advice

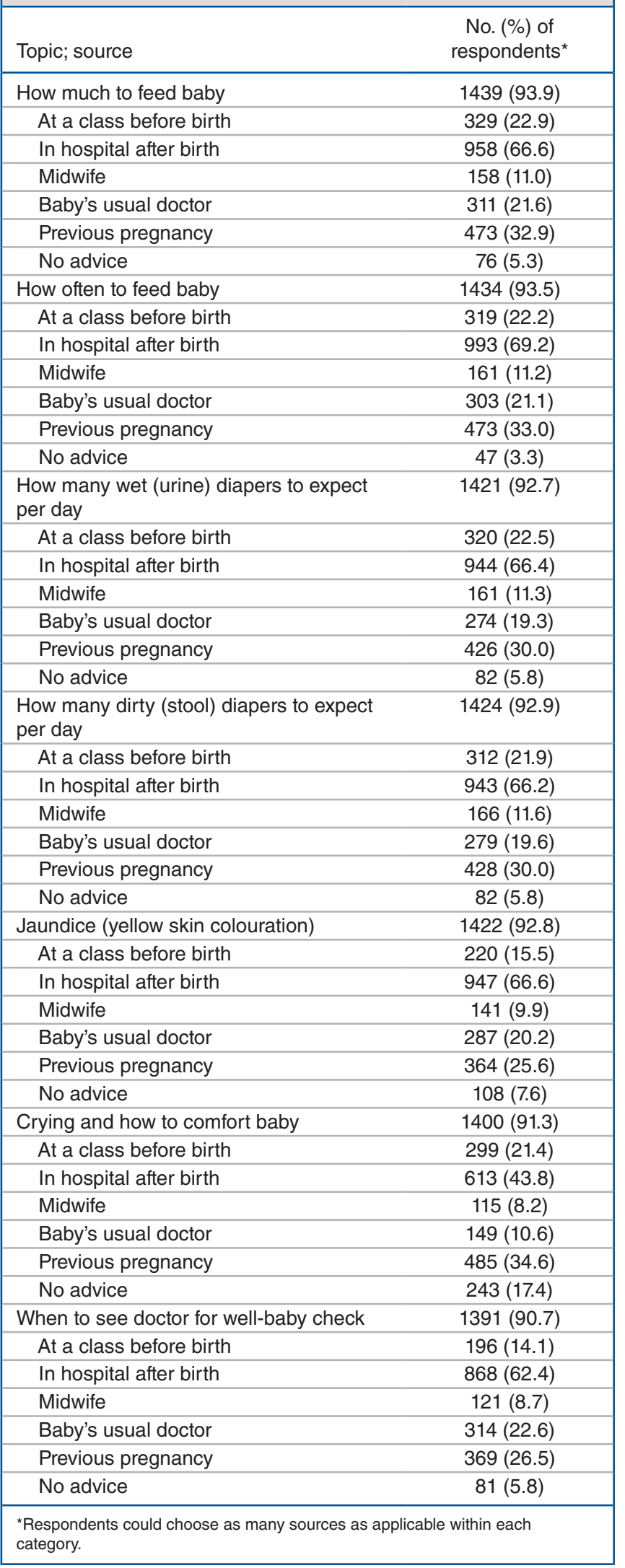

information on a broad range of topics, and they rated human-based resources, including more ready access to physicians or nurses, as potentially more helpful than further information-based resources, regardless of format. This underlines the potential positive impact of health care providers in the care of infants.

\section{Limitations}

Conducting the survey in large hospitals may have affected the generalizability of our findings to more rural settings. Although we knew the number of completed surveys and the number of potentially eligible neonates, we did not know the number of surveys distributed and could not calculate a true response rate. We received surveys from $17.8 \%$ of all visits in the study period. The surveyed population closely reflects the age $^{24}$ and income ${ }^{25}$ of Ontario parents, but the surveyed parents were somewhat more educated than average, ${ }^{26}$ which may represent a response bias. There may have been selection bias in those who chose to complete the survey. The fact that patients requiring resuscitation were excluded may have decreased our numbers of more severe presentations. Recall bias may have affected answers to questions about more remote times, including pregnancy and visits to the emergency department with other children. Comments by emergency department staff may have affected parents' interpretations of the seriousness of the illness compared to their decision to go to the emergency department. Finally, all data were selfreported and could not be correlated to final diagnosis or assessed severity in the emergency department.

\section{Conclusion}

Capitalizing on parents' reported confidence by providing families better supports to care for their baby at home or for the infant to be seen elsewhere than at the emergency department may decrease nonurgent emergency department use by neonates. Any such system would need to be immediately responsive, providing same-day support, to have the desired effect. Targeted interventions to decrease emergency department visits for gastrointestinal complaints may have a substantial effect on use, as these were by far the most common, as would community resources to ensure timely assessment for jaundice and support of feeding issues. Further studies are needed to determine which of the common presenting issues - such as jaundice, feeding problems, respiratory issues, crying and rash — may be amenable to education campaigns for families versus those more effectively dealt with through interventions aimed at health care providers or improving community resources.

\section{References}

1. Meara E, Kotagal UR, Atherton HD, et al. Impact of early newborn discharge legislation and early follow-up visits on infant outcomes in a state Medicaid population. Pediatrics 2004;113:1619-27.

2. Kotagal UR, Schoettker PJ, Atherton HD, et al. Relationship between early primary care and emergency department use in early infancy by the Medicaid population. Arch Pediatr Adolesc Med 2002;156:710-6.

3. Sharma V, Simon SD, Bakewell JM, et al. Factors influencing infant visits to emergency departments. Pediatrics 2000;106:1031-9.

4. Madden JM, Soumerai SB, Lieu TA, et al. Effects of a law against early postpartum discharge on newborn follow-up, adverse events, and HMO expenditures. N Engl 7 Med 2002;347:2031-8. 
5. Pomerantz WJ, Schubert CJ, Atherton HD, et al. Characteristics of nonurgent emergency department use in the first 3 months of life. Pediatr Emerg Care 2002;18:403-8

6. Kotagal UR, Atherton HD, Bragg E, et al. Use of hospital-based services in the first three months of life: impact of an early discharge program. $\mathcal{F}$ Pediatr 1997;130:250-6.

7. Goyal NK, Folger AT, Hall ES, et al. Effects of home visiting and maternal mental health on use of the emergency department among late preterm infants. 7 Obstet Gynecol Neonatal Nurs 2015;44:135-44.

8. Kennedy TJT, Purcell LK, LeBlanc JC, et al. Emergency department use by infants less than 14 days of age. Pediatr Emerg Care 2004;20:437-42.

9. Donovan EF, Perlstein PH, Atherton HD, et al. Prenatal care and infant emergency department use. Pediatr Emerg Care 2000;16:156-9.

10. Lee HC, Bardach NS, Maselli JH, et al. Emergency department visits in the neonatal period in the United States. Pediatr Emerg Care 2014;30:315-8.

11. Table 13-10-0418-01: Live births and fetal deaths (stillbirths), by type of birth (single or multiple). Ottawa: Statistics Canada; (modified 2018 Aug. 30). Available: https:// www150.statcan.gc.ca/t1/tbl1/en/tv.action?pid=1310042801\&pickMembers\%5B $0 \% 5 \mathrm{D}=1.7$ (accessed 2018 Aug. 30).

12. Andersen R. A behavioral model of families' use of health services. Chicago: Center for Health Administration Studies, University of Chicago; 1968.

13. Harris PA, Taylor R, Thielke R, et al. Research electronic data capture (REDCap) - a metadata-driven methodology and workflow process for providing translational research informatics support. 7 Biomed Inform 2009;42: 377-81.

14. Farion KJ, Wright $M$, Zemek R, et al. Understanding low-acuity visits to the pediatric emergency department. PLoS One 2015;10:e0128927.

15. Hummel K, Mohler MJ, Clemens CJ, et al. Why parents use the emergency department during evening hours for nonemergent pediatric care. Clin Pediatr (Phila) 2014;53:1055-61.

16. O'Donnell HC, Colman G, Trachtman RA, et al. Impact of newborn follow-up visit timing on subsequent ED visits and hospital readmissions: an instrumental variable analysis. Acad Pediatr 2014;14:84-91.

17. Flanagan CF, Stewart M. Factors associated with early neonatal attendance to a paediatric emergency department. Arch Dis Child 2014;99:239-43.

18. Batu ED, Yeni S, Teksam O. The factors affecting neonatal presentations to the pediatric emergency department. 7 Emerg Med 2015;48:542-7.

19. Smith V, Justafa M, Grafstein E, et al. Factors influencing the decision to attend a pediatric emergency department for nonemergent complaints. Pediatr Emerg Care 2015;31:640-4.

20. Kubicek K, Liu D, Beaudin C, et al. A profile of nonurgent emergency department use in an urban pediatric hospital. Pediatr Emerg Care 2012;28:977-84.

21. Swavely D, Baker K, Bilger K, et al. Understanding nonurgent pediatric emergency department visits: using hospital and family-centric data to inform system redesign. 7 Nurs Care Qual 2015;30:366-72.

22. Sturm JJ, Hirsh D, Weselman B, et al. Reconnecting patients with their primary care provider: an intervention for reducing nonurgent pediatric emergency department visits. Clin Pediatr (Phila) 2014;53:988-94.

23. Barr RG, Rajabali F, Aragon M, et al. Education about crying in normal infants is associated with a reduction in pediatric emergency room visits for crying complaints. 7 Dev Behav Pediatr 2015;36:252-7.

24. Data analysis for annual report 2014-2016. Ottawa: BORN Ontario; 2016. Available: www.bornontario.ca/assets/documents/Annual\%20report\%202014 -2016\%20-\%20Data\%20Slides.pdf (accessed 2018 Apr. 17).
25. Census profile. 2016 census. Ontario [Province] and Canada [Country] (table). Ottawa: Statistics Canada; 2017. Cat no 98-316-X2016001. Available: http:// www12.statcan.gc.ca/census-recensement/2016/dp-pd/prof/index.cfm?Lang=E (accessed 2018 Apr. 17).

26. Education highlight tables, 2016 census. Ottawa: Statistics Canada; (modified 2017 Nov. 23). Available: http://www12.statcan.gc.ca/census-recensement/2016/ $\mathrm{dp}$-pd/hlt-fst/edu-sco/Table.cfm? Lang=E\&T=22\&Geo=00\&View=2\&Age $=2$ $\& \mathrm{SP}=2$ (accessed 2018 Apr. 17).

Affiliations: Department of Pediatrics (Harrold, Langevin, Barrowman, Lacaze-Masmonteil, Zemek), Children's Hospital of Eastern Ontario; Children's Hospital of Eastern Ontario Research Institute (Harrold, Barrowman, Sprague, Fell, Moreau, Zemek); Better Outcomes Registry \& Network Ontario (Sprague); School of Epidemiology and Public Health (Fell) and Faculty of Education (Moreau), University of Ottawa, Ottawa, Ont.; Department of Pediatrics (Lacaze-Masmonteil), Cumming School of Medicine, University of Calgary, Calgary, Alta.; The Hospital for Sick Children (Schuh); University of Toronto (Schuh), Toronto, Ont.; Children's Hospital (Joubert), Schulich School of Medicine and Dentistry, Western University; Children's Health Research Institute (Joubert), London, Ont.; Department of Pediatrics (Moore), Queen's University, Kingston, Ont.; McMaster University (Solano); Department of Pediatrics (Solano), McMaster Children's Hospital, Hamilton, Ont.

Contributors: JoAnn Harrold, Mélissa Langevin, Nick Barrowman, Ann Sprague, Deshayne Fell, Katherine Moreau, Thierry Lacaze-Masmonteil and Roger Zemek conceived and designed the study. JoAnn Harrold, Mélissa Langevin, Katherine Moreau and Roger Zemek designed and tested the survey instrument. Suzanne Schuh, Gary Joubert, Andrea Moore and Tanya Solano acquired the data. JoAnn Harrold, Mélissa Langevin, Nick Barrowman, Ann Sprague, Deshayne Fell, Katherine Moreau, Thierry Lacaze-Masmonteil and Roger Zemek analyzed and interpreted the data. JoAnn Harrold drafted the manuscript. All of the authors critically revised the manuscript for important intellectual content, gave final approval of the version to be published and agreed to be accountable for all aspects of the work.

Funding: The study was supported by an Academic Health Science Centre Alternate Funding Plan Innovation grant.

Acknowledgements: The authors thank Ottawa-based freelance editor Joan Ramsay for her assistance with the manuscript and Lubna Salman and Vid Bijelic for their work on the data analysis. They also thank their site research assistants: Avery Yandt and Samantha Somers (Ottawa), Judy Sweeney and Maggie Rumantir (Toronto), Adriana Breen (Kingston), Cindy Langford (London) and Mandy Van Goch (Hamilton).

Supplemental information: For reviewer comments and the original submission of this manuscript, please see www.cmajopen.ca/content/6/3/ E423/suppl/DC1. 